\title{
Comunicação
}

[Communication]

\section{Eurytoma sp. (Hymenoptera: Pteromalidae) como parasitóide de Fannia pusio (Wiedemann) (Diptera: Fanniidae) no Brasil}

\author{
[Eurytoma sp. (Hymenoptera: Pteromalidae) as a parasitoid of Fannia pusio (Wiedemann) \\ (Diptera: Fanniidae) in Brazil] \\ C.H. Marchiori \\ Centro Federal de Educação Tecnológica de Urutaí-UNED-Morrinhos \\ Caixa Postal 92 \\ 75650-000 - Morrinhos, GO
}

Galinhas poedeiras em granjas provocam acúmulo de esterco, um excelente substrato para a proliferação de moscas. Para controle desses insetos, sugere-se um programa de manejo que integre métodos culturais, químicos e biológicos. Os agentes de controle biológico terão maior chance de sucesso se forem mais adaptados à região, à época do ano e ao tipo de esterco do local (Costa et al., 2004).

Os adultos de Fannia pusio (Wiedemann, 1830) (Diptera: Fanniidae) são freqüentemente encontrados em ambientes modificados pelo homem, e as larvas o são em matéria orgânica em decomposição (Pont, 1977; Marchiori e Prado, 1995; Marchiori e Prado, 1996; Marchiori et al., 2000).

O gênero Eurytoma, uma espécie cosmopolita, de biologia extremamente variada, inclui indivíduos fitófagos e carnívoros. A maioria é parasitóide solitário (Hanson e Gauld, 1995).

O objetivo deste trabalho foi relatar a primeira ocorrência do parasitóide Eurytoma sp. parasitando F. pusio no Brasil.

O experimento foi realizado na granja da Chácara Casa do Campo, em Itumbiara $\left(18^{\circ} 25^{\prime} \mathrm{S}\right.$ e $\left.49^{\circ} 13^{\prime} \mathrm{W}\right)$, Goiás. As fezes coletadas originaram-se de 40 aves da linhagem "Hyline".
A granja é composta por um galpão construído segundo os padrões recomendados para aves de postura. O piso abaixo das gaiolas e ao redor é constituído por terra. As fezes acumuladas sob as gaiolas variaram de umidade, de pastosas a firmes. As fezes frescas (pastosa), coletadas imediatamente após a emissão e colocadas em cinco bacias de $30 \mathrm{~cm}$ de diâmetro por $12 \mathrm{~cm}$ de altura, foram deixadas no próprio ambiente, em local seco, durante 15 dias. Daí foram levadas para o laboratório, para a extração das pupas, pelo método da flutuação, onde foram contadas e individualizadas em cápsulas de gelatina (número 00) até a emergência das moscas e/ou dos seus parasitóides. Os parasitóides e as moscas emergidos, identificados com auxílio de um microscópio estereoscópio, foram posteriormente conservados em álcool 70\%. O experimento foi realizado de abril a outubro de 2006.

Coletaram-se 153 espécimes de $F$. pusio, dos quais emergiram dois exemplares do parasitóide Eurytoma ${ }^{l}$. A porcentagem de parasitismo foi de 1,3\%. Em Itumbiara, F. pusio foi encontrada parasitada por Pachycrepoideus vindemmiae (Rondani, 1875) (Hymenoptera: Pteromalidae), Spalangia nigra Latrielle, 1805 (Hymenoptera: Pteromalidae) Paraganaspis egeria Díaz, Gallardo \& Walsh, 1996 (Hymenoptera: Figitidae) e Spalangia drosophilae Ashmead,

${ }^{1}$ Identificados pelo Dr. Valmir Antônio Costa, do Instituto Biológico de Campinas, SP.
Recebido em 2 de março de 2007

Aceito em 15 de maio de 2007

E-mail: chmarchiori@yahoo.com.br 
1887 (Hymenoptera: Pteromalidae) (Marchiori et al., 2005).

No Estado de São Paulo, Eurytoma sp. foi encontrada parasitando Musca domestica L. (Diptera: Muscidae), Stomoxys calcitrans (L.)
(Diptera: Muscidae) e Muscina stabulans (Fallén) (Diptera: Muscidae) (Costa et al., 2004). Este trabalho registra a primeira ocorrência de Eurytoma sp. parasitando F. pusio no Brasil.

Palavras-chave: Hymenoptera, Diptera, fezes de galinha, primeira ocorrência, Brasil

\section{ABSTRACT}

This study reports, for the first time, the occurrence of Eurytoma sp. (Hymenoptera: Pteromalidae) as parasitoid of Fannia pusio (Wiedemann) (Diptera: Fanniidae) found in chicken dung in Itumbiara, Goiás, Brazil. Manure samples, collected at two weeks intervals, were taken to the laboratory and the pupae were extracted by water flotation. Each pupa was placed in capsules of colorless gelatin until the emergence of dipterous or their parasitoids. The parasitism was $1.3 \%$.

Keywords: Hymenoptera, Diptera, chicken dung, parasitoid

\section{REFERÊNCIAS BIBLIOGRÁFICAS}

COSTA, V.A.; BERTI FILHO, E.; SILVEIRA NETO, S. Parasitóides (Hymenoptera: Chalcidoidea) de moscas sinantrópicas (Diptera: Muscidae) em aviários de Echaporã, SP. Arq. Inst. Biol., v.71, p.203-209, 2004.

HANSON, P.E.; GAULD, I.D. The Hymenoptera of Costa Rica. Oxford: Oxford University, 1995. 893p.

MARCHIORI, C.H.; PRADO, A.P. Longevidade e fecundidade de Fannia pusio (Wiedemann, 1830) (Diptera: Fanniidae) em laboratório. Rev. Bras. Biol., v.55, p.571-575, 1995.

MARCHIORI, C.H.; PRADO, A.P. Efeito da temperatura no desenvolvimento dos estágios imaturos de Fannia pusio (Wiedemann, 1830) (Diptera: Fanniidae) em laboratório. Rev. Bras. Biol., v.56, p.93-98, 1996.

MARCHIORI, C.H.; CASTRO, M.E.V.; PAIVA, T.C.G. et al. Dípteros muscóides de importância médica e veterinária e seus parasitóides em Goiás. Arq. Bras. Med. Vet. Zootec., v.52, p.350-353, 2000.

MARCHIORI, C.H.; SILVA FILHO, O.M.; FORTES, F.C.A. et al. Parasitóides de Fannia pusio (Wiedemann, 1830) (Diptera: Fanniidae) coletados em Caldas Novas, Goiás, Brasil. Ciênc. Agrotec., v.29, p.1288-1291, 2005.

PONT, A.C. A revision of Australian Fanniidae (Diptera: Calyptrate). Aust. J. Zoo., v.1, p.1-60, 1977. 